Pitcher, D. Face Processing and TMS. The Oxford Handbook of Transcranial Stimulation

$\underline{\left(2^{\text {nd }} \text { Edition }\right)}$. Oxford University Press.

\title{
Face Processing and TMS
}

\author{
David Pitcher
}

Department of Psychology, University of York, Heslington, York, YO105DD, U.K.

Corresponding author: David Pitcher: david.pitcher@york.ac.uk

Department of Psychology, University of York, Heslington, York, YO10 5DD, U.K

\section{Abstract}

Faces are rich sources of social information that simultaneously convey someone's identity, attentional focus, and emotional state. Humans process this wealth of socially relevant information in a network of face-selective regions distributed across the brain. In this chapter I review studies that have used transcranial magnetic stimulation (TMS) to study the cognitive operations and functional connections of the face network. TMS has been used to disrupt brain areas contributing to the processing of facial identity, facial expression, eye-gaze direction, head direction, trustworthiness and the auditoryvisual integration of speech. TMS has also been combined with neuroimaging to map how transient disruption of a targeted face area impacts connectivity across the face network. I also review chronometric TMS studies that have established when faces are processed across different brain areas down to a millisecond resolution. 


\section{Introduction}

Face-selective areas are found across the entire brain (Figure 1). This makes the study of the face network an excellent proxy model for studying the brain as a network. In addition, because the functional roles of these face-selective regions have been extensively studied with neuroimaging, the face network is an excellent model system in which to establish how complex cognitive operations (e.g. facial expression recognition and facial identity recognition) are processed across different brain areas (Allison et al., 2000, Kanwisher and Yovel, 2006, Pitcher et al., 2011c, Todorov, 2012).

Neuropsychological studies of patients with face-selective deficits, or prosopagnosia, have provided the strongest evidence that faces are processed in a functionally specific cortical network, but such patients are rare (Sergent and Signoret, 1992, Barton et al., 2002, Rossion et al., 2003, Rezlescu et al., 2014, Susilo et al., 2015). It is also rare to have pre-morbid data from these patients. So we cannot know the location of their faceselective areas, or have measures of their behavioral face recognition abilities prior to the incident that caused their prosopagnosia (Farah, 2004). In addition, studies of neuropsychological patients must account for any compensatory neural plasticity that may have occurred after the incident, leading to changes in their behavioral performance (Robertson and Murre, 1999).

Transiently disrupting face-selective regions with transcranial magnetic stimulation (TMS) in neurologically normal experimental participants is not limited by these issues. TMS studies enable researchers to systematically build on more than two hundred 
years of neuropsychological research. This chapter describes studies that have used TMS to systematically disrupt face-selective regions while participants performed concurrent behavioral tasks which measured different aspects of face processing (e.g. identify or facial expression discrimination). TMS has also been combined with fMRI to measure how transient disruption of a targeted face-selective region impacts other faceselective regions (Pitcher et al., 2014, Pitcher et al., 2017, Handwerker et al., 2020).

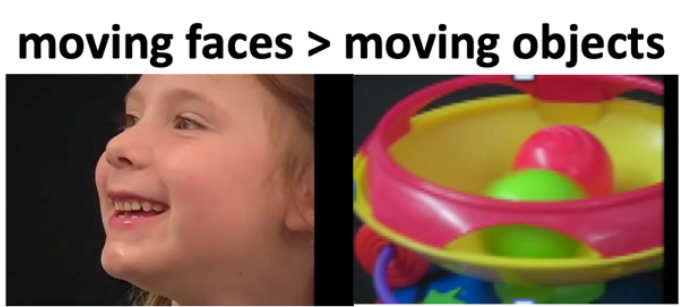

$N=52(p=0.0001)$

Cluster corrected $<50$ voxels

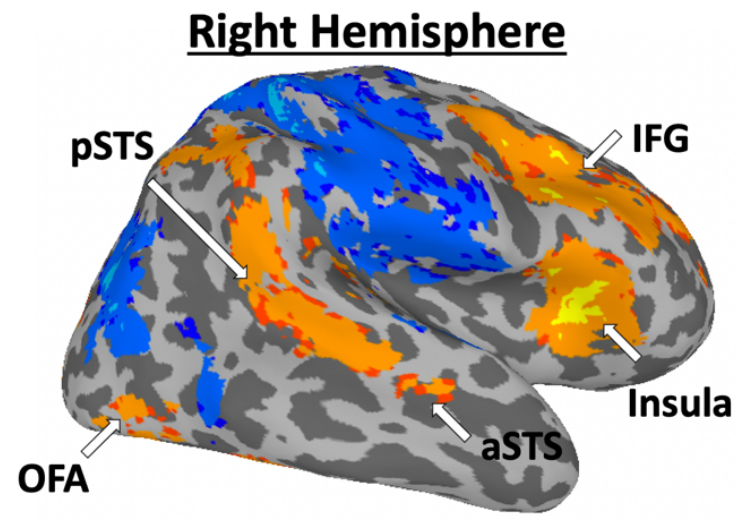

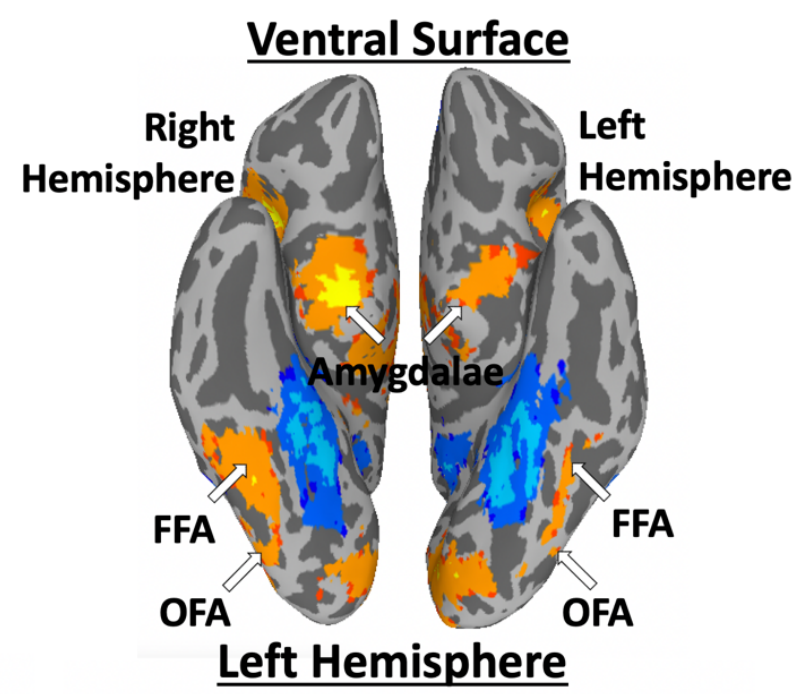

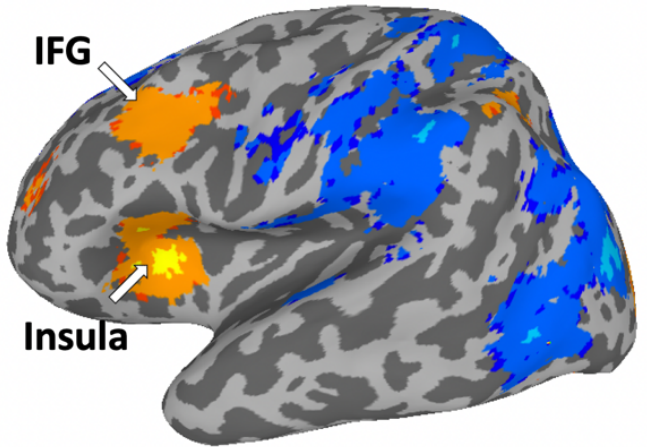

Figure 1. Group whole brain analysis $(N=52)$ showing a contrast of moving faces (orange) greater than moving objects (blue) (Pitcher et al., 2011a). Results show face-selective voxels in the core areas of the face network, the occipital face area (OFA), fusiform face area (FFA) and superior temporal sulcus (STS). Faceselective voxels were also seen in the amygdala, insula and inferior frontal gyrus (IFG). 


\section{The Face Network}

Models of face perception (Figure 2) propose that recognizing someone's identity, as opposed to recognizing their facial expression, are dissociable cognitive processes (Bruce and Young, 1986) that are preferentially processed in different parts of the brain (Haxby et al., 2000, Calder and Young, 2005). These different functions are preferentially processed in two functionally distinct face processing pathways that begin in occipitotemporal cortex. The ventral pathway, that includes the fusiform face area (FFA) (Kanwisher et al., 1997, McCarthy et al., 1997) preferentially processes invariant facial aspects, such as individual identity (Grill-Spector et al., 2004, Rotshtein et al., 2005). The lateral pathway, that includes the face-selective area in the posterior superior temporal sulcus (pSTS) (Puce et al., 1996) preferentially processes changeable facial aspects such as facial expression and eye gaze direction (Hoffman and Haxby, 2000, Winston et al., 2004). Despite these functional differences both pathways are thought to begin in the occipital face area (OFA) (Gauthier et al., 2000), an area that acts as the gateway for the extended face processing network (Figure 2).

The OFA, FFA and pSTS are often referred to as the core areas of the network because they are involved in the visual analysis of faces. Haxby et al. (2000) proposed that these core areas are functionally connected to other brain areas that preferentially process a range of cognitive functions. These include the intraparietal sulcus (attention), auditory cortex (speech perception) and the anterior temporal lobe (person specific identity 
information). There are also connections to multiple brain areas that process emotion, these include the amygdala, insula, limbic system and the somatosensory cortex.

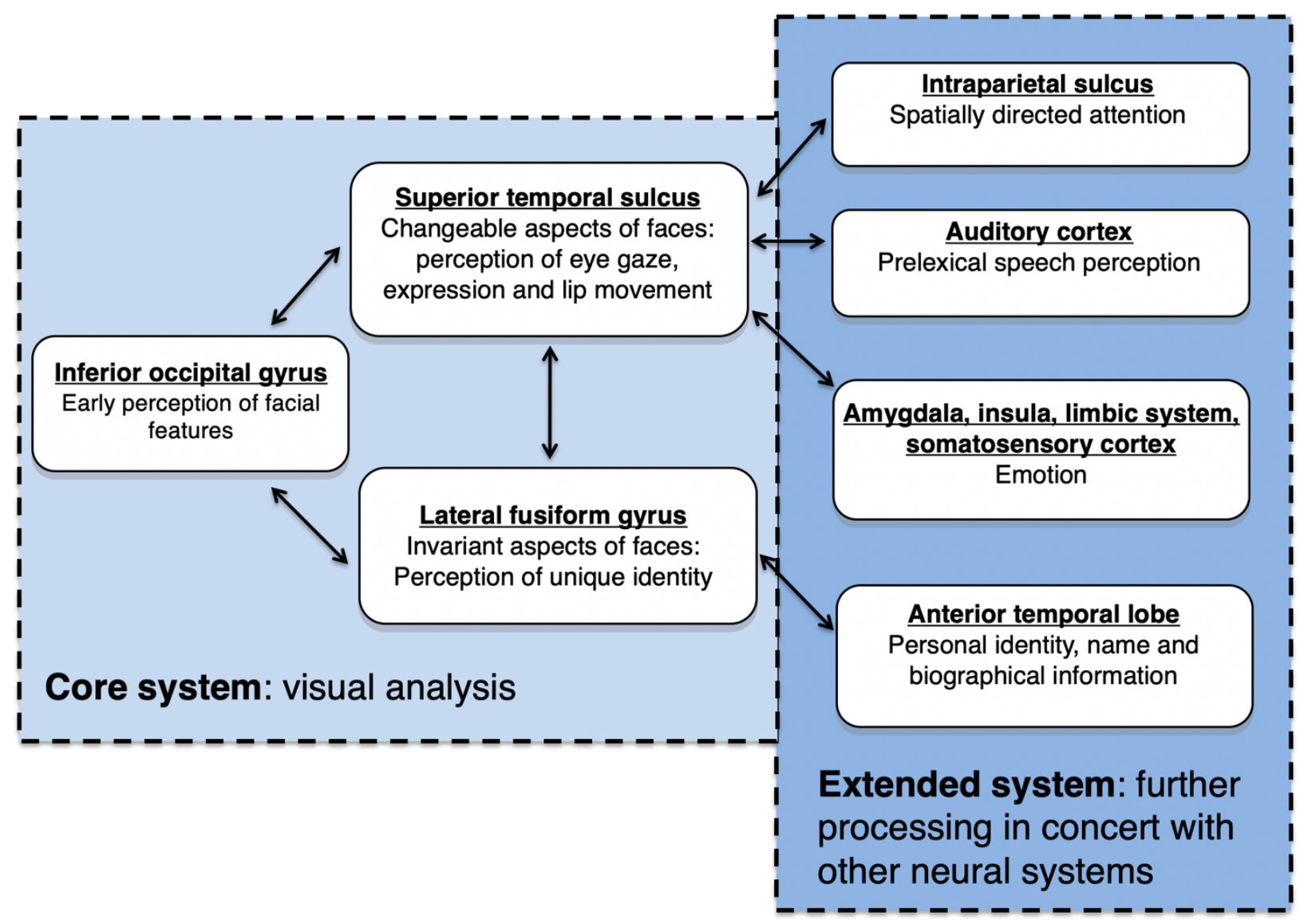

Figure 2. The extended face network, adapted from the original model by Haxby et al. (2000).

The spatial resolution of TMS is approximately 1 to $2 \mathrm{~cm}$ from the coil (Kammer, 1999).

This limits the number of areas in the face network that can be directly stimulated in TMS studies. To date, areas in the face network that have been directly targeted include the OFA (Pitcher et al., 2007), the pSTS (Pourtois et al., 2004), the parietal cortex (Beck 
et al., 2006), the somatosensory cortex (Pitcher et al., 2008). Other areas such as the FFA and the amygdala remain outside the effective range of direct stimulation. One way to study the effects of transient disruption in these deeper face areas is to combine TMS with functional magnetic resonance imaging (fMRI). Neural activity can be measured across the face network using fMRI before and after lateral face-selective areas such as the OFA or pSTS are stimulated. The remote effects of this stimulation can then be measured in remote areas such as the FFA (Pitcher, 2014) and the amygdala (Pitcher et al., 2017, Handwerker et al., 2020).

\section{Combining TMS with fMRI to study face network connectivity}

As stated above, existing models propose that the OFA is the sole entry point for the extended face network (Haxby et al., 2000, Calder and Young, 2005). Other models have challenged this hypothesis by proposing that there are multiple face pathways with independent cortical inputs from early visual cortex. Neuroimaging studies of healthy participants demonstrate that the pSTS exhibits a greater response to moving faces, more than static faces, while the OFA and FFA show little or no preference for moving faces (LaBar et al., 2003, Fox et al., 2009, Schultz and Pilz, 2009, Pitcher et al., 2019). This preferential response to motion suggests that the pSTS is receiving functional input from the motion-selective brain area hMT+ (O'Toole et al., 2002). Anatomical studies in humans and macaques also report cortical connections between motion-selective areas and the STS (Boussaoud et al., 1990, Gschwind et al., 2012). This cortical pathway projects down the superior temporal sulcus and along the lateral brain surface. Finally, 
neuropsychological patients with lesions to brain areas where the OFA is typically located can still exhibit face-selective activity in the FFA and pSTS (Rossion et al., 2003, Steeves et al., 2006, Rezlescu et al., 2012) challenging the hypothesis that the OFA is sole entry point for the wider face network.

Pitcher et al. (2014) tested the hypothesis that there are two cortical pathways that project from early visual cortex into the face network in a combined TBS / fMRI study. TBS was delivered over the OFA, or the pSTS, while participants were scanned with fMRI while watching short videos of moving faces or static images taken from these videos. Results demonstrated that TBS delivered over the OFA and pSTS produced a dissociation in the impairment to moving and static faces in the pSTS. TBS delivered over the rpSTS only reduced the neural response to moving faces in the rpSTS, while TBS delivered over the OFA only reduced the neural response to static faces in the rpSTS. By contrast TBS delivered over the OFA only reduced the response to static faces in the FFA. This pattern of results is consistent with the hypothesis that changeable face information can reach the pSTS via cortico-cortical connections from early visual cortex that are independent of the OFA (O'Toole et al., 2002). This conclusion is consistent with a neuropsychological study of a prosopagnosic patient with a right ventral occipitotemporal lesion (Sliwinska et al., 2020a). The neural response in the patients right pSTS was comparable with control participants while the responses in his right OFA and FFA were impaired. 
Subsequent studies that have combined TBS with fMRI to study face processing have continued to focus on the functional connections of the pSTS. Non-human primate neuroanatomical studies report a cortical pathway projecting along the STS into the dorsal banks of the amygdala (Aggleton et al., 1980, Stefanacci and Amaral, 2000). Pitcher et al. (2017) combined TBS with fMRI to test whether they could identify causal evidence for this cortical pathway in the human brain. Results showed that TBS delivered over the right posterior superior temporal sulcus (rpSTS) reduced the neural response to moving faces not only in the rpSTS itself, but also in face-selective voxels in the right anterior superior temporal sulcus (raSTS) and in the right amygdala (Figure $3)$.

More recently a similar approach was used to study what effect TBS delivered over the rpSTS would have the functional connectivity of the extended face processing network (Handwerker et al., 2020). Participants were scanned using resting-state fMRI (rsfMRI) before, and after, TBS was delivered over the rpSTS or the right motor cortex. TBS delivered over the rpSTS caused a network-wide reduction in resting-state connectivity across the extended face-processing network. This connectivity reduction was observed not only between the rpSTS and other face-selective areas, but also between nonstimulated face-selective areas on the ventral and medial brain surfaces (e.g. between right fusiform face area and the bilateral amygdalae). This demonstrates that TBS delivered over a single node in a brain network reduces the functional connectivity 
between the distributed nodes of that extended network. Crucially, this disruption was observed between remote nodes that had not been stimulated.
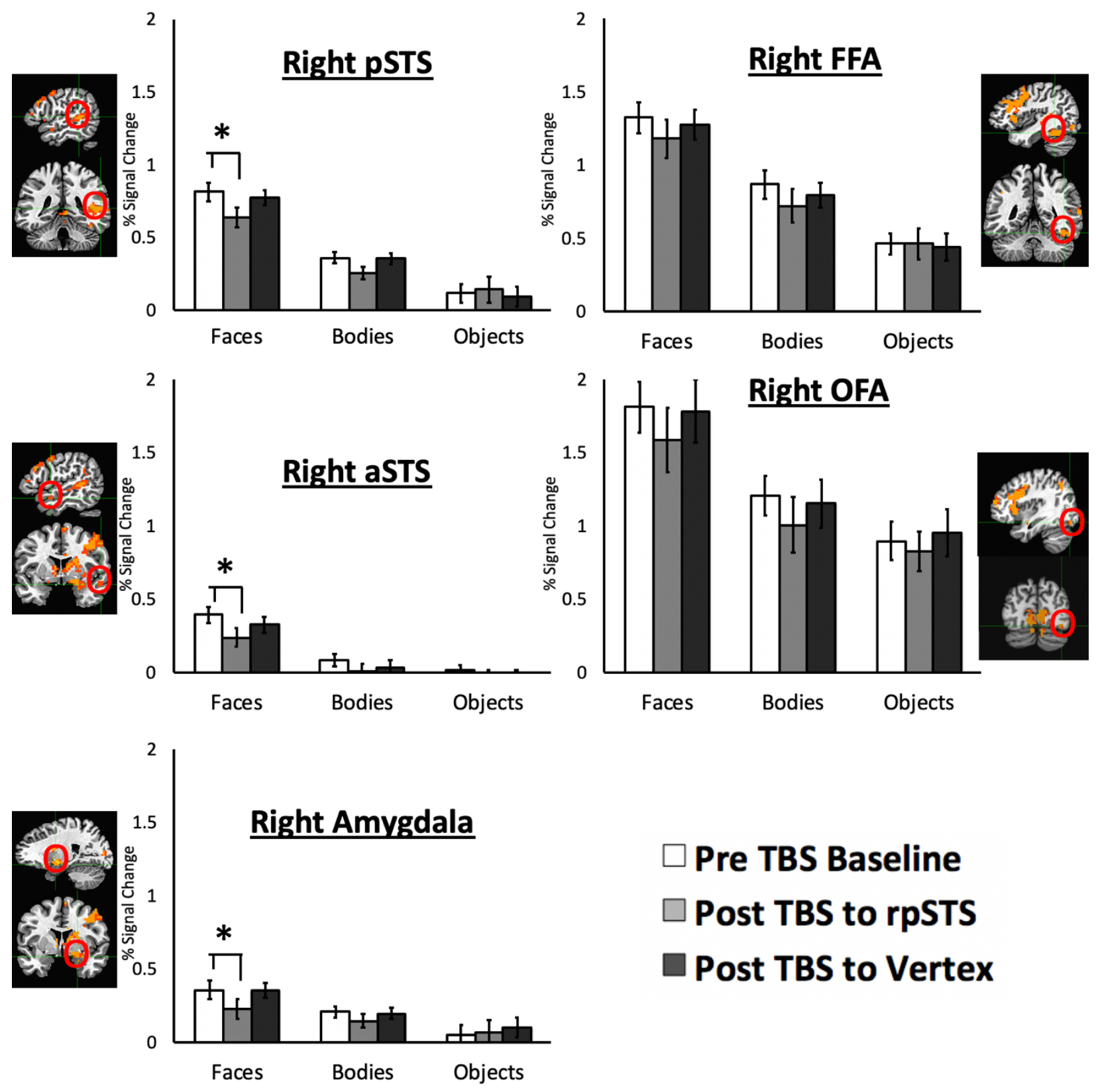

Figure 3. The results of Pitcher et al. (2017). Percent signal change data for the dynamic face, body and object stimuli before and after TBS in the five core regions-of-interest (ROIs): the rpSTS, raSTS, right amygdala, rFFA, and rOFA (Error bars denote Standard Errors). Brain slices show examples of the faceselective (dynamic faces $>$ dynamic objects) ROIs in a typical participant. TBS 
delivered over the rpSTS selectively and significantly reduced the BOLD response to dynamic faces only in the rPSTS, raSTS and right amygdala (* denotes significant effects).

\section{TMS studies of facial Identity}

Neuroimaging studies have identified different brain areas that contribute to facial identity recognition; these include the FFA (Grill-Spector et al., 2004), the anterior temporal lobe (Ramon et al., 2015) and the hippocampus (O'Neil et al., 2013). All are outside the effective range of TMS precluding the direct stimulation of these areas while participants perform facial identity discrimination tasks. Because of this limitation the studies that have used TMS to study facial identity recognition have largely focused on the occipital face area (OFA) (Gauthier et al., 2000).

As stated earlier, the OFA is the earliest face-selective area in the visual hierarchy and is thought to preferentially process the component parts of the face (Haxby et al., 2000). This has been causally demonstrated in studies showing that TMS delivered over the right OFA impairs the discrimination of face parts, such as the eyes and the mouth (Pitcher et al., 2007, Kadosh et al., 2011). Interestingly the perception of face parts has also been disrupted by TMS delivered over the left middle frontal gyrus (BA8) suggesting that higher cortical areas may be interacting with visual areas in the perception of facial features (Renzi et al., 2013). This study also demonstrated that TMS delivered over the right inferior frontal gyrus (BA44) disrupted a task in which participants had to judge the spacing between face parts (also configural processing). 
Disruption of configural face processing has also been demonstrated by TMS delivered over the posterior parietal cortex (Zachariou et al., 2017).

Face parts have also been manipulated in TMS studies that have used morphing software to create a gradual range between two different facial identities (Pitcher et al., 2009, Dilks et al., 2013). These studies demonstrated that TMS delivered over the right OFA disrupted the accurate discrimination of faces but had no effect on tasks using matched control stimuli (e.g. objects, bodies and scenes). Other studies have shown that TMS delivered over the right OFA disrupted the participants ability to match faces of two different identities using face stimuli that had been balanced for contrast, spectral power and brightness (Bona et al., 2018) or had been cropped to remove all external features (e.g. face shape and hair) (Solomon-Harris et al., 2013). These results again demonstrate that the stimuli in identity discrimination tasks of the OFA typically use faces that have subtle physical differences. This is consistent with the functional profile of the OFA which generates an early physical representation of a face. While it is clear that accurate perception of the component parts of a face contributes to identity recognition it is more likely that the holistic integration of an entire face is being processed when recognizing a face. The fact that a TMS OFA study that used color photographs of celebrities failed to find any effect of facial identity processing is also consistent with this conclusion (Gilaie-Dotan et al., 2010). 
The most compelling TMS evidence that the OFA is causally involved in processing facial identity comes from three recent studies from Ambrus and colleagues (Ambrus et al., 2017b, Ambrus et al., 2017a, Ambrus et al., 2019). These studies elegantly investigated the feedforward and feedback connections thought to exist between the OFA and the higher face processing areas process the invariant physical representations of unique facial identities (e.g. the FFA and anterior temporal lobe). In their first study participants learnt the faces of two previously unknown individuals using a sorting task that required identifying 60 unique photographs of two different people (Ambrus et al., 2017b). Results showed that TMS delivered over the right OFA impaired the participants ability to accurately the learn facial identities compared to TMS delivered the vertex control site.

Subsequent studies demonstrated that TMS delivered over the OFA impaired the priming of famous faces (Ambrus et al., 2017a) and the priming of names with famous faces (Ambrus et al., 2019). Taken together these studies demonstrate that the lowlevel face processing that occurs in the OFA causally contributes to more complex face computations in higher face-selective areas. A causal connection between the OFA and FFA has been demonstrated in neurologically normal participants in combined TMS / fMRI studies. These studies demonstrated that offline TMS delivered over the right OFA reduced the BOLD response to faces in the right FFA only (Pitcher et al., 2014) and the bilatateral FFA (Solomon-Harris et al., 2016). Future combined TMS / fMRI studies will 
hopefully further investigate the remote effects of targeted focal disruption in the OFA across the extended face network.

\section{TMS studies of facial expression}

TMS has also proven to be an effective experimental tool to study facial expression processing. This is, at least partly, because many of the brain areas involved in processing expressions are located on the lateral brain surface and can be directly stimulated with TMS. TMS studies of expression processing have targeted the OFA (Pitcher et al., 2008), the posterior STS (Pourtois et al., 2004, Sliwinska and Pitcher, 2018, Sliwinska et al., 2020b), premotor cortex (Balconi et al., 2014), the face area in the somatosensory cortex (Pitcher et al., 2008), medial prefrontal cortex (Mattavelli et al., 2013), dorsolateral prefrontal cortex (Zwanzger et al., 2014) and the cerebellum (Ferrari et al., 2018). The fact that expressions are processed across so many areas distributed across the brain demonstrates the saliency of the face when conveying emotion.

Neuroimaging studies have consistently identified the posterior STS as a locus of facial expression processing (Allison et al., 2000). Despite this extensive fMRI evidence, the

first TMS study to target the area reported TMS delivered over the right pSTS impaired an eye-gaze task, but had no effect on a facial expression task (Pourtois et al., 2004). However, this study used only two facial expressions (happy and fearful). This lack of variety in facial expressions may account for the lack of TMS induced impairment. 
Subsequent studies by Pitcher and colleagues using a wider range of expressions (happy, fearful, sad, angry, surprise and disgust) have reported impairments when targeting the right pSTS (Pitcher, 2014, Pitcher et al., 2020, Sliwinska and Pitcher, 2018).
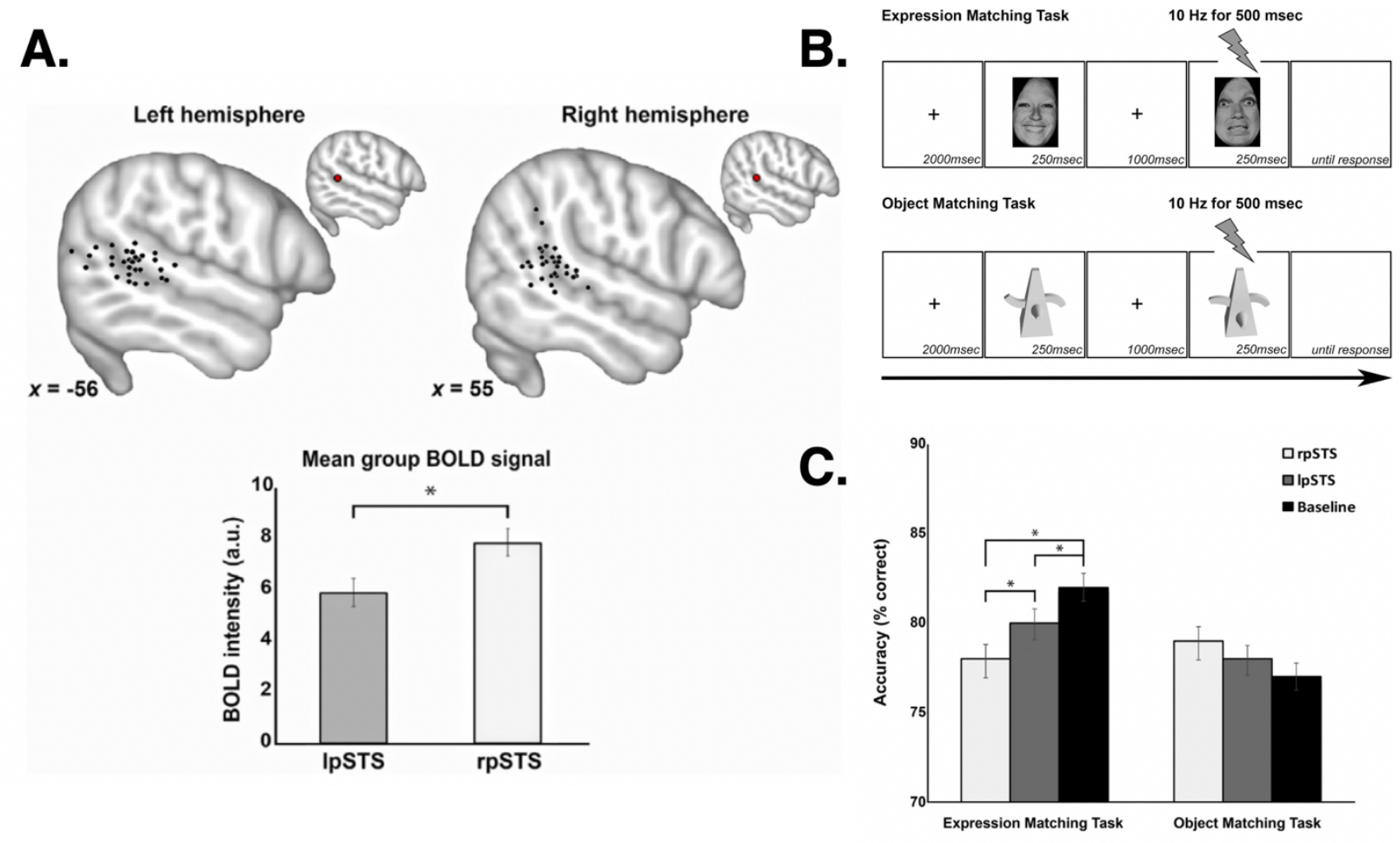

Figure 4. Sliwinska and Pitcher (2018) demonstrated that TMS delivered over the rpSTS and IPSTS impaired facial expression recognition. A. fMRI analysis showed that the right pSTS had a higher neural response to moving faces than the left pSTS. B. Participants then performed recognition tasks on facial expressions and objects while TMS was delivered over the right and left pSTS. C. TMS results were consistent with the fMRI results. TMS delivered over the right pSTS produced a greater impairment than TMS delivered over the left pSTS. This suggests that cognitive functions that are seemingly lateralized still rely on processing across both hemispheres for optimum task performance.

TMS can also be used to systematically investigate the laterality of facial expression processing in the pSTS. Sliwinska and Pitcher (2018) demonstrated this by stimulating 
the right and the left pSTS in a group of thirty participants while they performed a delayed match to sample expression recognition task (Figure 4). Results showed that TMS delivered over the right pSTS impaired task performance to a greater extent than TMS delivered over the left pSTS. But crucially, TMS delivered over the left pSTS still impaired task performance more than TMS to vertex control site. This result suggests that cognitive functions that are seemingly lateralized still rely on processing across both hemispheres for optimum task performance.

TMS has also been used to test embodied cognition models of facial expression recognition. Theories of embodied cognition propose that recognizing facial expressions is not only visual process. It also depends on somatosensory and motor areas that internally simulate the observed emotion, and that this process aids expression recognition (Niedenthal, 2007). This has been causally demonstrated in TMS studies that delivered TMS over the left premotor cortex (Enticott et al., 2008, Balconi et al., 2014). Rochas et al. (2013) also reported that TMS delivered over the left presupplementary motor area (pre-SMA) selectively impaired the recognition of happy faces but not fearful or angry faces. Finally both Pourtois et al. (2004) and Pitcher et al. (2008) have demonstrated that TMS delivered over the right somatosensory cortex also disrupts the recognition of facial expressions.

Frontal areas have also been targeted with TMS to disrupt facial expression recognition. Mattavelli et al. (2011) demonstrated that TMS delivered over the medial prefrontal 
cortex (mPFC) significantly increased response latencies on congruent trials in a priming study that matched words (happy or angry) and facial expressions. The same authors extended this result in a later study by again targeting the mPFC in a combined TMS with EEG design (Mattavelli et al., 2016). Results showed that TMS delivered over the MPFC reduced two separate face-selective EEG responses recorded from occipital areas peaking at 100 and $170 \mathrm{~ms}$ after stimulus onset. The mPFC was also targeted in an exciting study that went beyond basic facial expressions to demonstrate the area was causally involved in judgments of facial trustworthiness (Ferrari et al., 2016). Dzhelyova et al. (2011) also demonstrated that TMS delivered over the right pSTS disrupted judgments of trustworthiness based on facial features.

Zwanzger et al. (2014) investigated the causal role of the right dorsolateral prefrontal cortex (DLPFC) in a combined TMS / MEG study. TMS delivered over the right DLPFC increased the MEG response to fearful faces in a time-interval that occurred 110 to 170ms after stimulus onset. These demonstrations that TMS delivered over frontal areas can modulate responses recorded from posterior brain areas demonstrate the functional connections between face-selective areas in the occipitotemporal cortex. This is consistent with TMS studies demonstrating that TMS delivered over the OFA impairs expression recognition (Pitcher et al., 2008, Yaple and Vakhrushev, 2016).

\section{Chronometric TMS studies of face processing}


Chronometric TMS can be used to investigate when a targeted brain area is causally engaged in processing the concurrently performed behavioural task. Single pulses of TMS are typically delivered over the target region at different time points after stimulus onset or after the commencement of behavioural monitoring (Amassian et al., 1993). Plotting the temporal pattern of the induced behavioural impairments reveals when the stimulated area is causally engaged in task performance. Single pulse TMS delivered systematically at different time intervals (e.g. 10ms apart) can give a very precise representation of the temporal activation pattern but it does require a large number of temporal conditions when covering longer time periods (e.g. a time window ranging from 0 to $200 \mathrm{~ms}$ with pulses delivered every $10 \mathrm{~ms}$ would require twenty-one different conditions). One way to reduce the number of conditions and expand the duration of the induced disruption is to use two pulses. This is well established in the physiological domain and has been adapted for behavioural experiments. Double pulse TMS separated by $40 \mathrm{~ms}$ has proven to be a reliable protocol for demonstrating when a variety of functionally distinct cortical areas exhibit peak processing (O'Shea et al., 2004).

The first chronometric TMS study of face recognition (Pitcher et al., 2007) directly tested the hypothesis that the OFA is preferentially engaged in the processing of face part at an early stage of the face recognition process. TMS was delivered over the right and left OFA while participants performed a delayed match to sample discrimination task with face and house stimuli. These stimuli systematically manipulated either the parts of the 
faces (the eyes and mouth) and the houses (the windows and door) or the spacing between these parts. Results showed that TMS disrupted the discrimination of the face part task only when delivered over the right OFA (there was a non-significant trend at the left OFA). TMS had no effect on the face spacing task or either of the house tasks. While this result demonstrates that the OFA was selectively impaired only for face part discrimination, it does not address when the OFA was causally processing these face parts. This was addressed in a follow-up experiment in which double pulse TMS (pulses separated by $40 \mathrm{~ms}$ ) was delivered over the OFA at different latencies after stimulus onset ranging from $20 \mathrm{~ms}$ to $250 \mathrm{~ms}$. Intriguingly, TMS only impaired task accuracy when it was delivered 60 and $100 \mathrm{~ms}$ after stimulus onset. Taken together the results of this study demonstrate not only that the OFA is causally engaged in face part processing but also that it does so at a very early latency after stimulus onset.

This approach of conducting an initial TMS study to show an area is causally engaged in a task, and then following this with a chronometric TMS study to reveal when that area is causally active offers a powerful way to study the brain. Beauchamp et al. (2010) used just such an approach in an elegant TMS study of the McGurk effect. In an initial experiment TMS delivered over the right pSTS impaired participants ability to perceive McGurk stimuli, but not the non-McGurk control stimuli. Then in a follow-up experiment the authors delivered single pulse TMS (pulses separated by 100ms) over the right pSTS at different latencies ranging from minus $300 \mathrm{~ms}$ to post $300 \mathrm{~ms}$ after stimulus onset. Intriguingly TMS only disrupted task performance in a temporal window ranging 
from minus $100 \mathrm{~ms}$ to post $100 \mathrm{~ms}$ demonstrating when the integration of visual and auditory information was being computed in the targeted brain area.

Chronometric TMS studies of the face processing are especially useful because they can be used to causally track the processing speed of face perception across the nodes of the face network. Pitcher and colleagues have used this approach in two papers to trace the speed of facial expression recognition (Figure 5). In the first study participants performed a delayed match to sample facial expression recognition task while double pulse TMS (separated by 40ms) was delivered over the right OFA and right somatosensory cortex (SC) (Pitcher et al., 2008). TMS was delivered at different latencies after presentation of the match stimulus ranging from $20-60 \mathrm{~ms}, 60-100 \mathrm{~ms}$, $100-140 \mathrm{~ms}, 130-170 \mathrm{~ms}, 170-210 \mathrm{~ms}$ and $210-250 \mathrm{~ms}$ (these latencies were chosen to target face-selective ERP components that peak at 100ms and 170ms).

Results showed TMS disrupted expression recognition at $60-100 \mathrm{~ms}$ only when delivered over the right OFA, and at 100-140ms and 130-170ms when delivered over the right SC. In a follow-up study (Pitcher, 2014) the same TMS protocol was repeated but the right OFA and the right posterior superior temporal sulcus (pSTS) were stimulated. Results showed the same impairment window at the right OFA (60-100ms) and a similar early (but longer) impairment window at the right pSTS (60-140ms). Taken together, the results of these studies causally demonstrate the speed at which facial expression recognition is processed from posterior to more anterior face areas in the 
human brain. Such timing information is essential when understanding the functional connections and the direction of these connections in brain networks (Figure 5).

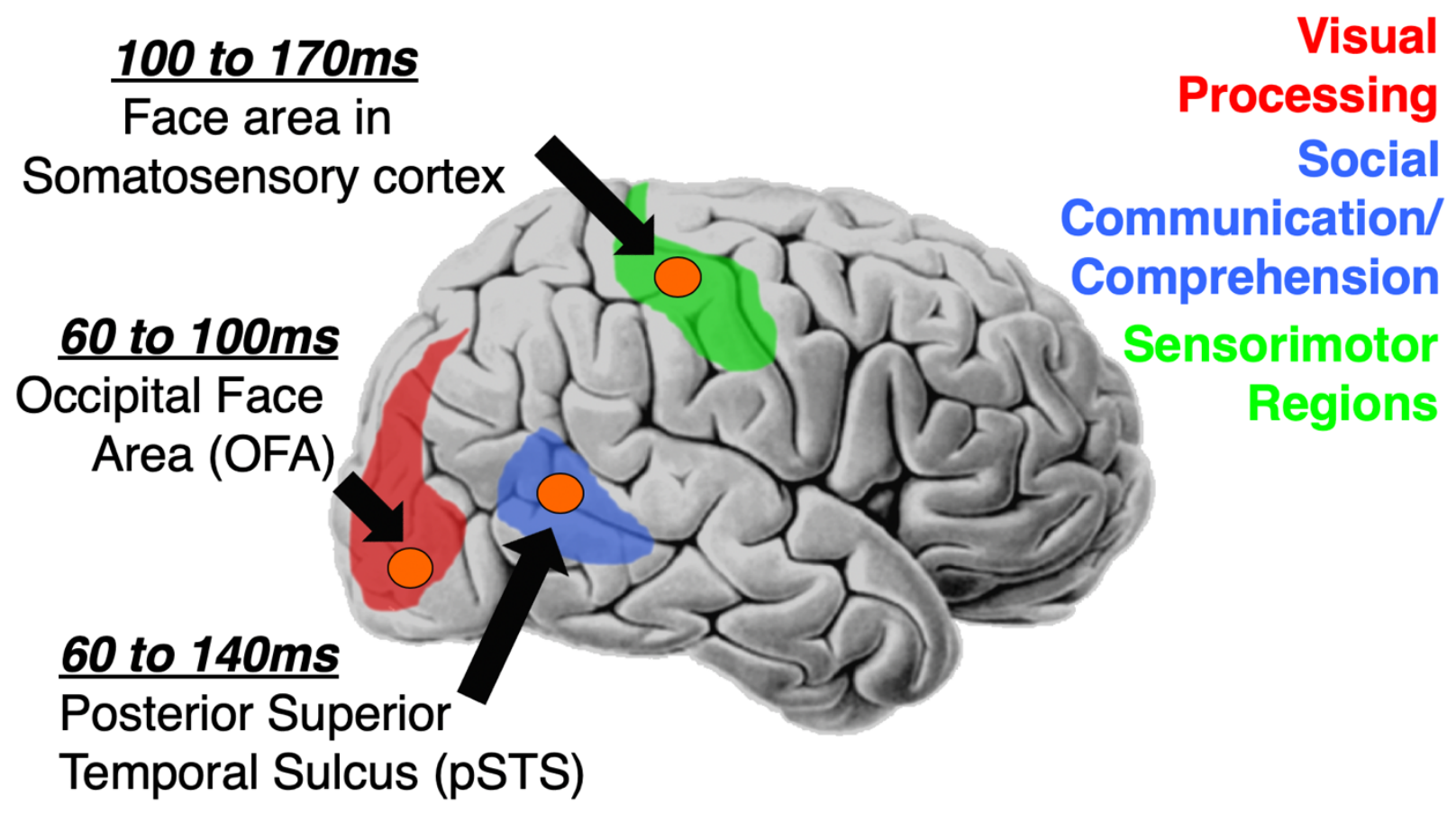

Figure 5. TMS studies (Pitcher et al., 2008, Pitcher, 2014) can trace the causal time-course of facial expression recognition across multiple brain areas. In these studies, double pulse TMS (pulses separated by $40 \mathrm{~ms}$ ) was delivered at different latencies after stimulus onset over the right occipital face area (OFA), right posterior superior temporal sulcus (pSTS) and the face area in the right somatosensory cortex (SC). Results show similar early latency impairments at the OFA and pSTS and a later latency impairment at the SC. Interesting the length of the impairment is longer in the higher brain areas (pSTS and SC) then in the OFA.

Interestingly the duration of the impairment window in the pSTS and somatosensory cortex was almost twice as long as the impairment window in the OFA. This difference in the length of the TMS impairment window is consistent with physiological evidence from non-human primates showing that the response profile of neurons in higher cortical 
regions is longer than the response in earlier cortical regions (Kovacs et al., 1995). Human fMRI evidence also shows that cortical regions in and around the rpSTS show a longer temporal response window to movie clips than regions in early visual cortex (Hasson et al., 2008). Future chronometric TMS studies can further address this question to investigate whether TMS can be used to measure the duration of cognitive functioning in different brain areas.

While chronometric TMS results give precise timing information for the causal engagement of specific face-selective areas they also raise questions with respect to other experimental methods with precise temporal resolution. Electroencephalography (EEG) and magnetoencephalography (MEG) studies of face perception report faceselective activity peaking at 100ms and 170ms (Bentin et al., 1996, Liu et al., 2002, Itier et al., 2006). These latencies are later than the TMS impairment windows observed at the OFA and pSTS (Pitcher et al., 2007, Pitcher et al., 2008, Pitcher, 2014) and only correspond to the later stages of the window at the somatosensory cortex. One possible explanation for this discrepancy is the fact that TMS studies are targeting a single face area while EEG and MEG studies are presumably recording the summation of activity from multiple brain areas. This summation may take longer.

A second possible explanation is the difference between the methods. TMS is disrupting a cognitive process, not recording the activity (from multiple brain areas) that contribute to that process. It is therefore possible that TMS delivered at the peak activity 
(corresponding with the EEG or MEG peak) is too late to have an effect because the corresponding processing has already occurred. However, TMS delivered while the neuronal activity that supports that cognitive process is building, may be sufficient to interrupt and impair performance on the concurrent behavioural task. There is nonhuman primate evidence to support this theory. Afraz et al. (2006) used microsimulation to disrupt face-selective cells in the inferotemporal cortex of macaques while they performed a face detection task. Results showed that stimulation delivered $50 \mathrm{~ms}$ prior to the peak local field potential (LFP) activity (at 150ms) produced a greater task performance impairment that stimulation delivered concurrently with that peak. This result, together with the human TMS results, suggests that brain stimulation methods that seek to disrupt task performance should target latencies when the neuronal activity in the stimulated areas is building, not when the activity peaks.

\section{Using TMS to study feedforward and feedback face processing}

Models of the face processing network propose that face-selective areas that preferentially process different cognitive functions share information related to the function being performed (Bruce and Young, 1986, Haxby et al., 2000). This necessitates the existence of bi-directional connections between face areas to facilitate the processing of incoming sensory information with information from areas performing other cognitive tasks. Chronometric TMS studies can be used to study the functions and timings of these feedforward and feedback processes. 
Pitcher et al. (2012) delivered double pulse TMS (pulses separated by 10ms) over the right OFA at different latencies after stimulus onset ranging from $20 \mathrm{~ms}$ up to $150 \mathrm{~ms}$ while participants performed face and body discrimination tasks. Results demonstrated that TMS delivered at 40/50ms impaired the discrimination of both faces and bodies, while TMS delivered at 100/110ms impaired the discrimination of faces only. This suggests that the OFA contributes to early face recognition (early meaning in the first $100 \mathrm{~ms}$ ) during two temporally and functionally distinct processing phases. The initial stage is domain general, and may reflect a very rapid feedforward pass of information into the visual system. This is followed by a later category-selective phase during which the face network selectively processes face information. Such processes are consistent with models of the primate visual system proposing that activity in higher cortical areas alters the activity in lower cortical areas via feedback processing mechanisms (Lamme and Roelfsema, 2000). Mattavelli and colleagues provided evidence consistent with this hypothesis in a combined TMS and EEG study of face processing (Mattavelli et al., 2013). TMS delivered over the medial prefrontal cortex 100ms after participants viewed faces with different facial expressions (happy, fear and neutral) reduced the faceselective P1 and N1 components recorded from the occipital electrodes.

Combining TMS and EEG offers a powerful experimental method for studying the temporal effects of disruption across the face network during feedforward face processing. Sadeh et al. (2011) delivered double pulse TMS (at 60 and 100ms) over the right OFA as participants viewed faces and bodies while simultaneously recording EEG. 
Results showed that TMS delivered over the OFA selectively enhanced the faceselective $\mathrm{N} 1$ component for faces, but had no effect on the $\mathrm{N} 1$ component for bodies. This result suggests that disruption of the OFA, the earliest stage of the face processing network, had a subsequent impact on face-selective areas at higher stages of the face network that are thought to contribute to the N1 component such as the FFA and the pSTS (Henson et al., 2003, Horovitz et al., 2004). Mattavelli and colleagues also used a combined TMS and EEG methodology to investigate conscious and unconscious face perception (Mattavelli et al., 2019). They again demonstrated that TMS delivered 60ms after stimulus onset had an effect on the $\mathrm{N} 1$ component and extended this result by demonstrating face specific effects in the EEG signal lasting up to $300 \mathrm{~ms}$ after faces were detected.

\section{TMS studies of Face Perception in the OFA}

TMS has also been used to study other aspects of face processing besides identity and expression recognition. The OFA is located in the lateral occipital cortex making it earliest region in the ventral visual processing stream that responds more to faces than to other stimulus categories. Network models propose that the OFA represents the more primitive, local, and stimulus-driven components (e.g. the eyes and the mouth) while the FFA represents invariant and global features that contribute to identity discrimination (Haxby et al., 2000, Taylor et al., 2010). This functional dissociation between the OFA and FFA was demonstrated in an fMRI adaptation study that compared the responses to physical changes in a face that changed the identity percept 
(Rotshtein et al., 2005). While the FFA responded only when the changes contributed to an identity change the OFA responded to physical changes in a face regardless of whether those changes contributed to participants perceiving a different facial identity.

Several TMS studies have demonstrated how the OFA is causally engaged in processing low level facial features. For example, Kietzmann et al. (2015) demonstrated that TMS delivered over the right OFA impaired judgments of viewpoint angle when faces were presented in the contralateral (but not the ipsilateral) visual field. The same study also demonstrated that TMS delivered over the right OFA impaired judgements of facial viewpoint symmetry in both visual fields. This causal role of the right OFA in facial symmetry detection was also demonstrated in a TMS study by Bona et al. (2015).

Mooney faces are black and white images that can be recognized as faces despite lacking any distinguishable local facial features. The fact that participants perceive Mooney faces as faces is taken as evidence that faces are processed using holistic mechanisms that integrate all the component parts of a face. Bona et al. (2016) demonstrated that TMS delivered over the right OFA impaired the discrimination of Mooney faces and Mooney objects. The authors interpret these results as demonstrating that the OFA plays a causal role in holistic recognition that is not specific to faces. This may be the case, but is also important to note that TMS studies that disrupt face recognition in the OFA typically use face stimuli in which facial features (e.g. the eyes and the mouth) have been altered (Pitcher et al., 2007, Dilks et al., 2013) 
and these local features are not apparent in Mooney faces. The face inversion effect, in which faces are more difficult to recognise when they are inverted, is also taken as evidence for the holistic processing of faces (Yin, 1970). TMS delivered over the right OFA has also been shown to disrupt recognition of face parts even when faces are inverted (Pitcher et al., 2011b) again demonstrating that the OFA is engaged in processing face parts.

\section{Conclusion}

The aim of this chapter has been to report the different brain areas and exciting approaches that have been used in TMS studies of face processing. A chapter published nine years ago in the Oxford Handbook of Face Perception reported on the five TMS papers that had been published on face processing up to that date (Pitcher et al., 2011d). The current chapter covers forty papers, demonstrating the growth of this area. Moreover, the past ten years have also seen studies that have combined TMS with EEG (Sadeh et al., 2011, Mattavelli et al., 2019) and TMS with fMRI (Pitcher, 2014, Pitcher et al., 2017, Handwerker et al., 2020) to study disruption across the extended face network. It is hoped that future TMS studies will continue to produce exciting and innovative insights into face processing in the coming years.221

\section{Acknowledgments}

DP is supported by BBSRC grant BB/P006981/1. 


\section{References}

AFRAZ, S. R., KIANI, R. \& ESTEKY, H. 2006. Microstimulation of inferotemporal cortex influences face categorization. Nature, 442, 692-5.

AGGLETON, J. P., BURTON, M. J. \& PASSINGHAM, R. E. 1980. Cortical and subcortical afferents to the amygdala of the rhesus monkey (Macaca mulatta). Brain Res, 190, 347-68.

ALLISON, T., PUCE, A. \& MCCARTHY, G. 2000. Social perception from visual cues: role of the STS region. Trends Cogn Sci, 4, 267-278.

AMASSIAN, V. E., CRACCO, R. Q., MACCABEE, P. J., CRACCO, J. B., RUDELL, A. P. \& EBERLE, L. 1993. Unmasking Human Visual-Perception with the Magnetic Coil and Its Relationship to Hemispheric-Asymmetry. Brain Research, 605, 312316.

AMBRUS, G. G., AMADO, C., KROHN, L. \& KOVACS, G. 2019. TMS of the occipital face area modulates cross-domain identity priming. Brain Struct Funct, 224, 149157.

AMBRUS, G. G., DOTZER, M., SCHWEINBERGER, S. R. \& KOVACS, G. 2017a. The occipital face area is causally involved in the formation of identity-specific face representations. Brain Struct Funct, 222, 4271-4282.

AMBRUS, G. G., WINDEL, F., BURTON, A. M. \& KOVACS, G. 2017b. Causal evidence of the involvement of the right occipital face area in face-identity acquisition. Neuroimage, 148, 212-218.

BALCONI, M., CANAVESIO, Y. \& FINOCCHIARO, R. 2014. Transcranial magnetic stimulation modulates left premotor cortex activity in facial expression recognition as a function of anxiety level. Translational Neuroscience, 5, 165-172.

BARTON, J. J. S., PRESS, D. Z., KEENAN, J. P. \& O'CONNOR, M. 2002. Lesions of the fusiform, face area impair perception of facial configuration in prosopagnosia. Neurology, 58, 71-78.

BEAUCHAMP, M. S., NATH, A. R. \& PASALAR, S. 2010. fMRI-Guided Transcranial Magnetic Stimulation Reveals That the Superior Temporal Sulcus Is a Cortical Locus of the McGurk Effect. Journal of Neuroscience, 30, 2414-2417.

BECK, D. M., MUGGLETON, N., WALSH, V. \& LAVIE, N. 2006. Right parietal cortex plays a critical role in change blindness. Cerebral Cortex, 16, 712-717.

BENTIN, S., ALLISON, T., PUCE, A., PEREZ, E. \& MCCARTHY, G. 1996. Electrophysiological Studies of Face Perception in Humans. J Cogn Neurosci, 8, 551-565.

BONA, S., CATTANEO, Z. \& SILVANTO, J. 2016. Investigating the Causal Role of rOFA in Holistic Detection of Mooney Faces and Objects: An fMRI-guided TMS Study. Brain Stimul, 9, 594-600.

BONA, S., SILVANTO, J. \& CATTANEO, Z. 2015. The causal role of right lateral occipital (LO) cortex and right occipital face area (OFA) in symmetry detection: evidences from fMRI-guided TMS data. Perception, 44, 265-266.

BONA, S., SILVANTO, J. \& CATTANEO, Z. 2018. TMS over right OFA affects individuation of faces but not of exemplars of objects. Neuropsychologia, 117, 364-370. 
BOUSSAOUD, D., UNGERLEIDER, L. G. \& DESIMONE, R. 1990. Pathways for Motion Analysis - Cortical Connections of the Medial Superior Temporal and Fundus of the Superior Temporal Visual Areas in the Macaque. Journal of Comparative Neurology, 296, 462-495.

BRUCE, V. \& YOUNG, A. 1986. Understanding face recognition. Br J Psychol, 77 ( Pt 3), 305-27.

CALDER, A. J. \& YOUNG, A. W. 2005. Understanding the recognition of facial identity and facial expression. Nat Rev Neurosci, 6, 641-51.

DILKS, D. D., JULIAN, J. B., PAUNOV, A. M. \& KANWISHER, N. 2013. The occipital place area is causally and selectively involved in scene perception. $J$ Neurosci, 33, 1331-6a.

DZHELYOVA, M. P., ELLISON, A. \& ATKINSON, A. P. 2011. Event-related Repetitive TMS Reveals Distinct, Critical Roles for Right OFA and Bilateral Posterior STS in Judging the Sex and Trustworthiness of Faces. Journal of Cognitive Neuroscience, 23, 2782-2796.

ENTICOTT, P. G., JOHNSTON, P. J., HERRING, S. E., HOY, K. E. \& FITZGERALD, P. B. 2008. Mirror neuron activation is associated with facial emotion processing. Neuropsychologia, 46, 2851-2854.

FARAH, M. J. 2004. Visual agnosia, Cambridge, Mass., MIT Press.

FERRARI, C., LEGA, C., VERNICE, M., TAMIETTO, M., MENDE-SIEDLECKI, P., VECCHI, T., TODOROV, A. \& CATTANEO, Z. 2016. The Dorsomedial Prefrontal Cortex Plays a Causal Role in Integrating Social Impressions from Faces and Verbal Descriptions. Cereb Cortex, 26, 156-65.

FERRARI, C., OLDRATI, V., GALLUCCI, M., VECCHI, T. \& CATTANEO, Z. 2018. The role of the cerebellum in explicit and incidental processing of facial emotional expressions: A study with transcranial magnetic stimulation. Neuroimage, 169, 256-264.

FOX, C. J., IARIA, G. \& BARTON, J. J. S. 2009. Defining the Face Processing Network: Optimization of the Functional Localizer in fMRI. Human Brain Mapping, 30, 1637-1651.

GAUTHIER, I., TARR, M. J., MOYLAN, J., SKUDLARSKI, P., GORE, J. C. \& ANDERSON, A. W. 2000. The fusiform "face area" is part of a network that processes faces at the individual level (vol 12, pg 499, 2000). Journal of Cognitive Neuroscience, 12, 912-912.

GILAIE-DOTAN, S., SILVANTO, J., SCHWARZKOPF, D. S. \& REES, G. 2010. Investigating representations of facial identity in human ventral visual cortex with transcranial magnetic stimulation. Front Hum Neurosci, 4, 50.

GRILL-SPECTOR, K., KNOUF, N. \& KANWISHER, N. 2004. The fusiform face area subserves face perception, not generic within-category identification. Nat Neurosci, 7, 555-62.

GSCHWIND, M., POURTOIS, G., SCHWARTZ, S., DE VILLE, D. V. \& VUILLEUMIER, P. 2012. White-Matter Connectivity between Face-Responsive Regions in the Human Brain. Cerebral Cortex, 22, 1564-1576. 
HANDWERKER, D., IANNI, G., GUTIERREZ, B., ROOPCHANSINGH, V., GONZALEZCASTILLO, J., CHEN, G., BANDETTINI, P., UNGERLEIDER, L. \& PITCHER, D. 2020. Thetaburst TMS to the human posterior superior temporal sulcus disrupts resting-state fMRI connectivity across the face processing network. Network Neuroscience.

HASSON, U., YANG, E., VALLINES, I., HEEGER, D. J. \& RUBIN, N. 2008. A hierarchy of temporal receptive windows in human cortex. $J$ Neurosci, 28, 2539-50.

HAXBY, J. V., HOFFMAN, E. A. \& GOBBINI, M. I. 2000. The distributed human neural system for face perception. Trends Cogn Sci, 4, 223-233.

HENSON, R. N., GOSHEN-GOTTSTEIN, Y., GANEL, T., OTTEN, L. J., QUAYLE, A. \& RUGG, M. D. 2003. Electrophysiological and haemodynamic correlates of face perception, recognition and priming. Cereb Cortex, 13, 793-805.

HOFFMAN, E. A. \& HAXBY, J. V. 2000. Distinct representations of eye gaze and identity in the distributed human neural system for face perception. Nature Neuroscience, 3, 80-84.

HOROVITZ, S. G., ROSSION, B., SKUDLARSKI, P. \& GORE, J. C. 2004. Parametric design and correlational analyses help integrating $\mathrm{fMRI}$ and electrophysiological data during face processing. Neuroimage, 22, 1587-95.

ITIER, R. J., HERDMAN, A. T., GEORGE, N., CHEYNE, D. \& TAYLOR, M. J. 2006. Inversion and contrast-reversal effects on face processing assessed by MEG. Brain Res, 1115, 108-20.

KADOSH, K. C., WALSH, V. \& KADOSH, R. C. 2011. Investigating face-property specific processing in the right OFA. Social Cognitive and Affective Neuroscience, 6, 58-65.

KAMMER, T. 1999. Phosphenes and transient scotomas induced by magnetic stimulation of the occipital lobe: their topographic relationship. Neuropsychologia, 37, 191-8.

KANWISHER, N., MCDERMOTT, J. \& CHUN, M. M. 1997. The fusiform face area: a module in human extrastriate cortex specialized for face perception. $J$ Neurosci, 17, 4302-11.

KANWISHER, N. \& YOVEL, G. 2006. The fusiform face area: a cortical region specialized for the perception of faces. Philos Trans R Soc Lond B Biol Sci, 361, 2109-28.

KIETZMANN, T. C., POLTORATSKI, S., KONIG, P., BLAKE, R., TONG, F. \& LING, S. 2015. The Occipital Face Area Is Causally Involved in Facial Viewpoint Perception. Journal of Neuroscience, 35, 16398-16403.

KOVACS, G., VOGELS, R. \& ORBAN, G. A. 1995. Cortical correlate of pattern backward masking. Proc Natl Acad Sci U S A, 92, 5587-91.

LABAR, K. S., CRUPAIN, M. J., VOYVODIC, J. T. \& MCCARTHY, G. 2003. Dynamic perception of facial affect and identity in the human brain. Cerebral Cortex, 13, 1023-1033.

LAMME, V. A. \& ROELFSEMA, P. R. 2000. The distinct modes of vision offered by feedforward and recurrent processing. Trends Neurosci, 23, 571-9. 
LIU, J., HARRIS, A. \& KANWISHER, N. 2002. Stages of processing in face perception: an MEG study. Nat Neurosci, 5, 910-6.

MATTAVELLI, G., CATTANEO, Z. \& PAPAGNO, C. 2011. Transcranial magnetic stimulation of medial prefrontal cortex modulates face expressions processing in a priming task. Neuropsychologia, 49, 992-998.

MATTAVELLI, G., PISONI, A., ROMERO LAURO, L. J., MARINO, B. F., BONOMI, M., ROSANOVA, M. \& PAPAGNO, C. 2019. TMS-EEG approach unveils brain mechanisms underlying conscious and unconscious face perception. Brain Stimul, 12, 1010-1019.

MATTAVELLI, G., ROSANOVA, M., CASALI, A. G., PAPAGNO, C. \& ROMERO LAURO, L. J. 2013. Top-down interference and cortical responsiveness in face processing: a TMS-EEG study. Neuroimage, 76, 24-32.

MATTAVELLI, G., ROSANOVA, M., CASALI, A. G., PAPAGNO, C. \& ROMERO LAURO, L. J. 2016. Timing of emotion representation in right and left occipital region: Evidence from combined TMS-EEG. Brain Cogn, 106, 13-22.

MCCARTHY, G., PUCE, A., GORE, J. C. \& ALLISON, T. 1997. Face-specific processing in the human fusiform gyrus. J Cogn Neurosci, 9, 605-10.

NIEDENTHAL, P. M. 2007. Embodying emotion. Science, 316, 1002-5.

O'NEIL, E. B., BARKLEY, V. A. \& KOHLER, S. 2013. Representational demands modulate involvement of perirhinal cortex in face processing. Hippocampus, 23, 592-605.

O'SHEA, J., MUGGLETON, N. G., COWEY, A. \& WALSH, V. 2004. Timing of target discrimination in human frontal eye fields. $J$ Cogn Neurosci, 16, 1060-7.

O'TOOLE, A. J., ROARK, D. A. \& ABDI, H. 2002. Recognizing moving faces: a psychological and neural synthesis. Trends in Cognitive Sciences, 6, 261-266.

PITCHER, D. 2014. Facial expression recognition takes longer in the posterior superior temporal sulcus than in the occipital face area. $J$ Neurosci, 34, 9173-7.

PITCHER, D., CHARLES, L., DEVLIN, J. T., WALSH, V. \& DUCHAINE, B. 2009. Triple dissociation of faces, bodies, and objects in extrastriate cortex. Curr Biol, 19, 319-24.

PITCHER, D., DILKS, D. D., SAXE, R. R., TRIANTAFYLLOU, C. \& KANWISHER, N. 2011a. Differential selectivity for dynamic versus static information in faceselective cortical regions. Neuroimage, 56, 2356-63.

PITCHER, D., DUCHAINE, B. \& WALSH, V. 2014. Combined TMS and FMRI reveal dissociable cortical pathways for dynamic and static face perception. Curr Biol, 24, 2066-70.

PITCHER, D., DUCHAINE, B., WALSH, V., YOVEL, G. \& KANWISHER, N. 2011b. The role of lateral occipital face and object areas in the face inversion effect. Neuropsychologia, 49, 3448-53.

PITCHER, D., GARRIDO, L., WALSH, V. \& DUCHAINE, B. C. 2008. Transcranial magnetic stimulation disrupts the perception and embodiment of facial expressions. J Neurosci, 28, 8929-33. 
PITCHER, D., GOLDHABER, T., DUCHAINE, B., WALSH, V. \& KANWISHER, N. 2012. Two critical and functionally distinct stages of face and body perception. $J$ Neurosci, 32, 15877-85.

PITCHER, D., IANNI, G. \& UNGERLEIDER, L. G. 2019. A functional dissociation of face-, body- and scene-selective brain areas based on their response to moving and static stimuli. Sci Rep, 9, 8242.

PITCHER, D., JAPEE, S., RAUTH, L. \& UNGERLEIDER, L. G. 2017. The Superior Temporal Sulcus Is Causally Connected to the Amygdala: A Combined TBSfMRI Study. J Neurosci, 37, 1156-1161.

PITCHER, D., PILKINGTON, A., RAUTH, L., BAKER, C., KRAVITZ, D. J. \& UNGERLEIDER, L. G. 2020. The Human Posterior Superior Temporal Sulcus Samples Visual Space Differently From Other Face-Selective Regions. Cereb Cortex, 30, 778-785.

PITCHER, D., WALSH, V. \& DUCHAINE, B. 2011c. The role of the occipital face area in the cortical face perception network. Exp Brain Res, 209, 481-93.

PITCHER, D., WALSH, V. \& DUCHAINE, B. 2011d. Transcranial magnetic stimulation studies of face processing. 362-378.

PITCHER, D., WALSH, V., YOVEL, G. \& DUCHAINE, B. 2007. TMS evidence for the involvement of the right occipital face area in early face processing. Curr Biol, 17, 1568-73.

POURTOIS, G., SANDER, D., ANDRES, M., GRANDJEAN, D., REVERET, L., OLIVIER, E. \& VUILLEUMIER, P. 2004. Dissociable roles of the human somatosensory and superior temporal cortices for processing social face signals. Eur J Neurosci, 20, 3507-15.

PUCE, A., ALLISON, T., ASGARI, M., GORE, J. C. \& MCCARTHY, G. 1996. Differential sensitivity of human visual cortex to faces, letterstrings, and textures: A functional magnetic resonance imaging study. Journal of Neuroscience, 16, 5205-5215.

RAMON, M., VIZIOLI, L., LIU-SHUANG, J. \& ROSSION, B. 2015. Neural microgenesis of personally familiar face recognition. Proc Natl Acad Sci U S A, 112, E4835-44.

RENZI, C., SCHIAVI, S., CARBON, C. C., VECCHI, T., SILVANTO, J. \& CATTANEO, Z. 2013. Processing of featural and configural aspects of faces is lateralized in dorsolateral prefrontal cortex: A TMS study. Neuroimage, 74, 45-51.

REZLESCU, C., BARTON, J. J. S., PITCHER, D. \& DUCHAINE, B. 2014. Normal acquisition of expertise with greebles in two cases of acquired prosopagnosia. Proceedings of the National Academy of Sciences of the United States of America, 111, 5123-5128.

REZLESCU, C., PITCHER, D. \& DUCHAINE, B. 2012. Acquired prosopagnosia with spared within-class object recognition but impaired recognition of degraded basic-level objects. Cogn Neuropsychol, 29, 325-47.

ROBERTSON, I. H. \& MURRE, J. M. 1999. Rehabilitation of brain damage: brain plasticity and principles of guided recovery. Psychol Bull, 125, 544-75.

ROCHAS, V., GELMINI, L., KROLAK-SALMON, P., POULET, E., SAOUD, M., BRUNELIN, J. \& BEDIOU, B. 2013. Disrupting pre-SMA activity impairs facial happiness recognition: an event-related TMS study. Cereb Cortex, 23, 1517-25. 
ROSSION, B., CALDARA, R., SEGHIER, M., SCHULLER, A. M., LAZEYRAS, F. \& MAYER, E. 2003. A network of occipito-temporal face-sensitive areas besides the right middle fusiform gyrus is necessary for normal face processing. Brain, 126, 2381-95.

ROTSHTEIN, P., HENSON, R. N., TREVES, A., DRIVER, J. \& DOLAN, R. J. 2005. Morphing Marilyn into Maggie dissociates physical and identity face representations in the brain. Nat Neurosci, 8, 107-13.

SADEH, B., PITCHER, D., BRANDMAN, T., EISEN, A., THALER, A. \& YOVEL, G. 2011. Stimulation of category-selective brain areas modulates ERP to their preferred categories. Curr Biol, 21, 1894-9.

SCHULTZ, J. \& PILZ, K. S. 2009. Natural facial motion enhances cortical responses to faces. Exp Brain Res, 194, 465-75.

SERGENT, J. \& SIGNORET, J. L. 1992. Varieties of functional deficits in prosopagnosia. Cereb Cortex, 2, 375-88.

SLIWINSKA, M. W., BEARPARK, C., CORKHILL, J., MCPHILLIPS, A. \& PITCHER, D. 2020a. Dissociable pathways for moving and static face perception begin in early visual cortex: evidence from an acquired prosopagnosic. Cortex

SLIWINSKA, M. W., ELSON, R. \& PITCHER, D. 2020b. Dual-site TMS demonstrates causal functional connectivity between the left and right posterior temporal sulci during facial expression recognition. Brain Stimul, 13, 1008-1013.

SLIWINSKA, M. W. \& PITCHER, D. 2018. TMS demonstrates that both right and left superior temporal sulci are important for facial expression recognition. Neuroimage, 183, 394-400.

SOLOMON-HARRIS, L. M., MULLIN, C. R. \& STEEVES, J. K. 2013. TMS to the "occipital face area" affects recognition but not categorization of faces. Brain Cogn, 83, 245-51.

SOLOMON-HARRIS, L. M., RAFIQUE, S. A. \& STEEVES, J. K. 2016. Consecutive TMS-fMRI reveals remote effects of neural noise to the "occipital face area". Brain Res, 1650, 134-141.

STEEVES, J. K., CULHAM, J. C., DUChAINE, B. C., PRATESI, C. C., VALYEAR, K. F., SCHINDLER, I., HUMPHREY, G. K., MILNER, A. D. \& GOODALE, M. A. 2006. The fusiform face area is not sufficient for face recognition: evidence from a patient with dense prosopagnosia and no occipital face area. Neuropsychologia, 44, 594-609.

STEFANACCI, L. \& AMARAL, D. G. 2000. Topographic organization of cortical inputs to the lateral nucleus of the macaque monkey amygdala: a retrograde tracing study. J Comp Neurol, 421, 52-79.

SUSILO, T., WRIGHT, V., TREE, J. J. \& DUCHAINE, B. 2015. Acquired prosopagnosia without word recognition deficits. Cogn Neuropsychol, 32, 321-39.

TAYLOR, J. C., ROBERTS, M. V., DOWNING, P. E. \& THIERRY, G. 2010. Functional characterisation of the extrastriate body area based on the N1 ERP component. Brain Cogn, 73, 153-9.

TODOROV, A. 2012. The role of the amygdala in face perception and evaluation. Motiv Emot, 36, 16-26. 
WINSTON, J. S., HENSON, R. N., FINE-GOULDEN, M. R. \& DOLAN, R. J. 2004. fMRIadaptation reveals dissociable neural representations of identity and expression in face perception. J Neurophysiol, 92, 1830-9.

YAPLE, Z. A. \& VAKHRUSHEV, R. 2016. Investigating Emotional Top Down Modulation of Ambiguous Faces by Single Pulse TMS on Early Visual Cortices. Front Neurosci, 10, 305.

YIN, R. K. 1970. Face recognition by brain-injured patients: a dissociable ability? Neuropsychologia, 8, 395-402.

ZACHARIOU, V., NIKAS, C. V., SAFIULLAH, Z. N., GOTTS, S. J. \& UNGERLEIDER, L. G. 2017. Spatial Mechanisms within the Dorsal Visual Pathway Contribute to the Configural Processing of Faces. Cereb Cortex, 27, 4124-4138.

ZWANZGER, P., STEINBERG, C., REHBEIN, M. A., BROCKELMANN, A. K., DOBEL, C., ZAVOROTNYY, M., DOMSCHKE, K. \& JUNGHOFER, M. 2014. Inhibitory repetitive transcranial magnetic stimulation (rTMS) of the dorsolateral prefrontal cortex modulates early affective processing. Neuroimage, 101, 193-203. 